\title{
CRÍTICA À PANACEIA PEDAGÓGICO-DESPORTIVA
}

\author{
Murilo Mariano Vilaça* \\ Bruno Gawryszewski** \\ Alexandre Palma***
}

\begin{abstract}
RESUMO
A ideia de que a prática desportiva é um eficaz instrumento para educar, incluir e transformar os jovens marginalizados, promovendo a paz, ordem e cidadania, tem sido reiterada constantemente. Educadores, mídia e a literatura científica sugestionam as pessoas a crerem em um "real poder" de transformá-los em "cidadãos de bem". Neste artigo, desenvolvemos os seguintes objetivos: (1) identificar uma possível relação entre os valores concernentes ao conceito de capital social e os objetivos daquela prática no que concerne à juventude marginalizada; (2) refletir sobre a violência enquanto um conceito e um fenômeno político, problematizando a sua negativização absoluta; e (3) apontar os limites daquela ideia, salientando as suas imprecisões conceituais e criticando seus objetivos. Nossa conclusão é que tal ideia está envolvida por um discurso prenhe de imprecisões e serve de fundamento para uma tecnologia social de pacificação que não altera substantivamente as condições de vida da população-alvo.
\end{abstract}

Palavras-chave: Esporte. Educação. Juventude marginalizada. Cidadania. Violência.

\footnotetext{
* Doutor em Filosofia (UFRJ) e em Educação (UERJ). Professor da Pós-Graduação em Pedagogia Crítica da Educação Física da Universidade Federal do Rio de Janeiro. Bolsista CAPES. E-mail: contatoacademico@hotmail.com

** Doutor em Educação (UFRJ). Professor da Escola Nacional de Circo (RJ). E-mail: brunog81@yahoo.com.br

*** Doutor em Saúde Pública pela Escola Nacional de Saúde Pública da FIOCRUZ. Professor da Escola de Educação Física e Desportos da Universidade Federal do Rio de Janeiro (EEFD-UFRJ). Docente da Pós-Graduação Stricto Sensu em Educação Física (EEFD-UFRJ). Bolsista CNPq PQ2.E-mail: palma_alexandre@yahoo.com.br
} 


\begin{abstract}
The idea that sports are effectively useful for changing, including and changing the life of marginalized youth by promoting peace, order and citizenship has been constantly reiterated. Educators, the mass media and the scientific literature have suggested people to believe sports can successfully change them into "good citizens". This article aims to: (1) identify a possible relation with the values concerning the idea of social capital and the objectives to be achieved concerning the marginalized youth; (2) think of violence as a concept and a political phenomenon by discussing that violence is not necessarily seen as something always negative; and (3) indicate the limits of that idea by explaining its misconceptions and criticizing its aims. We conclude that such idea is involved in a speech full of inaccuracies and it is basically a social technology for pacification which does not substantially modify the life of the marginalized youth.
\end{abstract}

Keywords: Sports. Education. Marginalized youth. Citizenship. Violence.

\title{
1 Apresentação
}

No presente artigo, analisamos a ideia profusamente divulgada de que a prática desportiva tem importantes funções sociais. Educar, socializar, incluir e transformar indivíduos são algumas delas. Sobretudo quando eles pertencem à classe empobrecida, o esporte é tido como um meio pedagógico destacadamente eficiente, sendo considerado uma verdadeira panaceia para os males que afligem a juventude marginalizada. Convergindo relativa ou absolutamente, muitos discursos associam a prática pedagógico-desportiva à solução de alguns dos mais antigos, importantes e complexos problemas que caracterizam as sociedades tidas como liberais e democráticas. Dentre eles, destacamos a íntima relação entre pobreza e as desigualdades com a mitigação da cidadania, a criminalidade e a violência endêmicas, como o estudo de Resende e Andrade (2011) mostra. Devido ao potencial e esperança depositados na educação pelo esporte, tal insinuante ideia apresenta-se como digna de atenção e exame crítico cada vez mais apurados.

Aqui, essa ideia será analisada e criticada quanto aos seus objetivos e conteúdo (aspecto teórico-normativo), mas também ao modo como estes são apresentados. Nossa abordagem será mediada por dois conceitos: 
capital social, porque ele pode ajudar a entender o que se pretende combater e promover com a prática pedagógico-desportiva; e violência, porque ela é apresentada como um mal que a formação de "cidadãos de bem” - principal finalidade dessa prática - pode combater.

Nossos objetivos são: (1) examinar o conceito de capital social ${ }^{1}$, a fim de identificar relações com o que a prática pedagógico-desportiva voltada àquela parcela da juventude visa promover; (2) analisar a violência enquanto um conceito e um fenômeno, refletindo teoricamente sobre sua polêmica dimensão política, para que compreendamos os interesses e limites da retórica da pacificação; e (3) criticar normativamente a panaceia desportiva, apontando os limites dos seus objetivos sociopolíticos e o modo pouco nítido de apresentar seus conceitos/valores centrais.

Em suma, a crítica concerne ao modo como os objetivos/conceitos são apresentados e ao seu conteúdo normativo: (1) porque o modo é impreciso, não revelando claramente que noção de conceitos, cuja semântica é variada e está em disputa, é adotada; (2) porque, via de regra, o conteúdo expressa uma restrita e questionável "tríade do bem", a saber, a promoção intransigente da paz, a manutenção da ordem e o respeito à lei e às autoridades, simplificando a noção de cidadania. Sem desvalorizar o esporte enquanto um fenômeno social com potencial educativo, defendemos a necessidade de limitar, precisar e contextualizar aquilo que lhe é devotado, contestando a formação de uma apologia unidirecional em torno dele.

\section{Funções sociais do esporte: traços de uma ideia panacéica}

Atualmente, o esporte tem sido relacionado à promoção de coisas como a ordem, paz e a cidadania, além do respeito à lei e à autoridade, combatendo a violência e marginalidade. Sob a questionável tese de que nele "todos têm a oportunidades de vencer" e que "como praticantes, todos, de algum modo saem ganhando", como problematicamente concluem

1 Como é um conceito polissêmico e utilizado por variados autores do campo das Ciências Sociais, ressaltamos que as perspectivas analisadas aqui são as de Francis Fukuyama e Robert Putnam. 
Azevedo e Gomes Filho (2011, p. 601), o esporte vem sendo propagado como um recurso eficiente na promoção e conservação de dado estado de coisas. Vianna e Lovisolo (2011) é um exemplo da exacerbação das funções sociais do esporte, bem como da mitigação da complexidade dos problemas que, em tese, poderia resolver:

O esporte é um meio importante de socialização por conseguir atingir valores como coletivismo, amizade e solidariedade, que são relevantes para vencer as agruras da pobreza. [...] O esporte é uma forma de substituir a violência, por uma competição controlada, em que o respeito à vida é um elemento fundamental. A procura do esporte pelos membros das classes populares, como um meio de elevação social, especialmente por aqueles que são residentes em comunidades violentas, pode representar uma forma de auto-realização e de superação da condição de não ter direitos de cidadania plena (p. 294).

A prática de atividades físicas ou desportivas - quer com estas denominações, quer não - é milenarmente compreendida como constitutiva da formação dos indivíduos para viverem em dada concepção de sociedade. Quer dizer, não é recente a compreensão de que ela possui funções sociopolíticas e estas não seriam nada modestas. A título de exemplo, Foucault (2006a) examina alguns textos clássicos da cultura grega antiga, notadamente o Primeiro Alcibiades, de Platão, mostrando como um dos imperativos ético-políticos daquela cultura - cuidado de siestava diretamente ligado à prática de exercícios físicos.

Inobstante sua antiguidade, nas últimas décadas, inclusive no Brasil, há uma notória ampliação do número de ocorrências dos discursos que esposam o papel social do esporte, além de uma intensificação da ênfase (VIANNA e LOVISOLO, 2009; VILAÇA, 2009). Geralmente, eles vinculam a prática desportiva à juventude carente ou em situação de risco social. Contudo, há casos em que o esporte tem sido considerado capaz de solucionar ou contribuir para a solução de outros problemas complexos em nível global. A série de reportagens intituladas Missão de Paz veiculada em um programa esportivo dominical de uma rede de televisão aberta ${ }^{2}$ é

2 As reportagens estão disponíveis no site <http://globoesporte.globo.com/programas/ esporte-espetacular/>. 
um exemplo controvertido. Nela, palavras e imagens são veiculadas sobre um fundo musical emotivo, apelando à sensibilidade do telespectador para persuadi-lo de que conflitos seculares que envolvem questões raciais, étnico-culturais e religiosas em várias partes do mundo podem ser contornados por meio da prática desportiva. No nosso entendimento, esta é uma extrema exacerbação do poder do esporte. Senão, teríamos encontrado o "remédio" (por sinal, bem simples) para males complexos como as guerras civis.

Mas o que tem motivado a aposta em tal ideário no tocante à juventude? Que crenças esta improvável panaceia desportiva gera? Os fatores e intenções são múltiplos. No caso específico do Brasil, podemos salientar dois motivadores. Primeiramente, Vianna e Lovisolo (2009) afirmam que esse ideário resulta do crescimento bastante relevante do número de projetos sociais esportivos voltados para os jovens das classes sociais populares, o que, segundo eles, aponta para um reconhecimento do esporte como canal de socialização positiva ou inclusão social. Não está claro, para nós, se este crescimento é causa ou resultado, mas há indícios de que há um vínculo de crescimento entre os projetos sociais e aquela ideia. O segundo fator são os recentes megaeventos que o país sediou e/ou sediará, tais como os Jogos Pan-Americanos, Copa do Mundo e os Jogos Olímpicos, os quais geram um grande apelo social capitalizado pelas mídias de massa (MELO, 2004; VILAÇA, 2009).

Esses fatores contam com uma espécie de campanha publicitária de promoção do esporte, legitimando um produto que tem alto valor de mercado. Organizações não governamentais por trás de projetos sociais em busca de financiamentos; empresas e governos atentos às oportunidades de lucros (lícitos e ilícitos) provenientes dos megaeventos, impactos econômicos que Domingues et al. (2011) analisam; bem como o interesse pela diversificação dos meios de "governo da pobreza" são alguns dos outros elementos relacionados. Como há necessidade de legitimação dos investimentos feitos e das mudanças "necessárias", a apologia ao papel social do esporte atua como subsídio retórico.

Além das grandes mídias, conforme analisa criticamente Vilaça (2009), a literatura científica, não só no Brasil, também é um meio socialmente legitimado que esposa e veicula a ideia de que o esporte 
inclui socialmente, transforma vidas e educa aqueles jovens (AZEVEDO; GOMES FILHO, 2011; BAILEY, 2005; BEUTLER, 2008; FRASERTHOMAS et al., 2005). Compreendido, por alguns, como um eficiente instrumento de educação/socialização/inclusão de jovens à beira do crime ${ }^{3}$, o esporte tem sido divulgado como um meio para a saída desta parcela da população da sua situação. A intenção é fazer crer que ele contribui para a formação de uma cultura de paz, combatendo a criminalidade e violência, incluindo e formando "bons cidadãos" para uma "sociedade democrática".

Entretanto, em conformidade com o que alguns autores vêm argumentando, uma das marcas da apologia ao esporte é a imprecisão e simplificação praticadas. Conceitos ou valores sociopolíticos, tais como paz, inclusão, cidadania, democracia não costumam ter contornos nítidos ou são concebidos de um modo bastante questionável (CORREIA, 2008; MELO, 2004; VILAÇA, 2009). Citando o conceito de cidadania, porque talvez seja o trunfo retórico daquela ideia, parece incontestável o equívoco de supor que haja uma única definição possível. Rodrigues (2006) defende que, ao se falar em cidadania, é fundamental determinar para qual tipo de democracia. Todavia, embora os apologetas da paneceia desportiva não a definam, seguem afirmando que o esporte forma cidadãos, como se isto fosse seu apanágio. Para tanto, por um lado, citam exemplos de indivíduos que se tornaram atletas; ou que ingressaram em universidades privadas via bolsa de estudos; ou que emigraram do seu local de origem. Além de serem questionáveis desde o ponto de vista da inclusão social e da promoção da democracia/cidadania, sabe-se que esses casos são exceções. Por outro, são citados exemplos que não seriam tão raros, mas que são igualmente questionáveis, como os jovens que não mais "perdem o seu tempo na rua sob más influências"; ou que demonstraram uma melhoria no quesito notas escolares (VILAÇA, 2009). Tais exemplos evidenciam parte das controversas visões de inclusão social e democracia adotadas.

3 Expressão usada no Informativo PRONASCI (Programa Nacional de Segurança Pública com Cidadania). Este programa foi criado pelo Ministério da Justiça do Governo Federal em 2008, visando articular políticas de segurança e ações sociais diversificadas a partir da cooperação entre forças de segurança pública e representantes da sociedade civil. Disponível em: <http://www.mj.gov.br/pronasci/data/Pages/MJA49D1180ITEMIDE10E2 DBCF99741E4AD6C9D3C91BDF979PTBRIE.htm>. Acesso em: 21 dez. 2008. 
Ao defender esse conceitualmente impreciso e pragmaticamente questionável poder esportivo parece se desconsiderar o fato de que aquilo que se quer combater é uma consequência complexa que denuncia um processo histórico de empobrecimento e marginalização a ser enfrentado e transformado. Para nós, estar-se-ia tergiversando ao fato de que a solução dos problemas é irredutível a qualquer ação isolada. A ideia de que os jovens empobrecidos e marginalizados social, economica e politicamente podem "mudar de vida" por meio dos ensinamentos e oportunidades advindas do esporte nos parece bastante equivocada.

\section{Capital social e participação política da juventude}

Segundo Santos e Baquero (2007), o capital social (doravante, CS) é uma alternativa teórico-explicativa às deficiências mostradas pelas democracias quanto à resolução de problemas sociais, econômicos e políticos, bem como à situação de incredibilidade e deslegitimação. Ele foi criado para promover "um cenário em que a democracia poliárquica convive pacificamente com problemas de crescente pobreza e exclusão social [...]" (BAQUERO; SANTOS, 2007, p. 221). Com ele, visava-se pensar em mecanismos de estabilidade fundados na confiança recíproca, na solidariedade e na participação comunitária pela associação informal em meio às desigualdades. Como algumas consequências de uma sociedade estruturalmente desigual representam óbices ao desenvolvimento do capitalismo, necessitava-se de uma forma de conjugar desenvolvimento econômico e coesão social.

O Banco Mundial criou um conjunto de capitais como critério de avaliação de projetos de desenvolvimento estatais na década de 1990. Dentre eles, figurava o CS. Embora haja muitas definições de CS, ele, grosso modo, refere-se às instituições, relações e normas sociais que dão qualidade às associações interpessoais numa dada sociedade (SANTOS; ROCHA, 2011). De acordo com Furlanetto (2008, p. 62) "existe certo consenso na literatura de que o capital social refere-se à habilidade dos indivíduos em garantir benefícios por meio de associação em redes de relações sociais "ou outras estruturas" alicerçadas por confiança, norma 
e costumes". Como a coesão social é tida como um fundamento para a prosperidade econômica e para o desenvolvimento sustentável, o CS funcionaria como uma "argamassa" que uniria as instituições e os cidadãos em busca do bem-estar comum (VILAÇA, 2010).

De acordo com D'Araujo (2003), Putnam entende que o desengajamento cívico, ou seja, um processo de afastamento de questões políticas, de interesse público, é um dos graves problemas atuais que põem em risco a sociabilidade. O CS quer dar conta da formação do que Putnam (2007) chama de comunidade cívica. Com uma visão neoinstitucionalista, Putnam parte da noção defendida por Tocqueville para analisar as razões do norte da Itália ser mais desenvolvido que o sul. Para ele, o elemento-chave era o desempenho institucional, que, por sua vez, dependia da natureza da vida cívica dos concidadãos. O engajamento cívico e a solidariedade social mediadas pela confiança mútua forjariam um associativismo horizontal, contribuindo para um bom desempenho institucional, pois as associações civis reforçariam a eficácia e estabilidade política e econômica dos governos democráticos (PUTNAM, 2007).

Tal perspectiva ressoa em outros autores. Segundo Fukyama (2002), o CS deve ser entendido como "um conjunto de valores ou normas informais partilhados por membros de um grupo que lhes permite cooperar entre si [...]. A confiança age como lubrificante levando qualquer grupo ou organização a funcionar com eficiência" (p. 155), de forma que a falta de confiança é a fonte fundamental dos problemas institucionais e sociais (FUKUYAMA, 1996). Diante deles, as bases da sociabilidade e da governabilidade têm o seu valor normativo e sua eficiência questionadas, produzindo um clima de desconfiança, descrédito e desrespeito generalizados, em conformidade com aquilo que preconiza Fukuyama (1996).

Santos e Rocha (2011), todavia, contestam esta ideia, afirmando que, isoladamente, a confiança não serve como medida para avaliar o CS de dada sociedade, muito menos é um índice fundamental para a democracia. A manutenção de uma ordem social também não o é. Esta visão é, no mínimo, mais pertinente. Afinal, que níveis e abrangência de valores como confiança, solidariedade e estabilidade seriam não só possíveis, mas, sobretudo, desejáveis ante um contexto de profundas desigualdades socioeconômicas e políticas? Uma sociedade desigual, mas estável, não representaria uma 
clara e reprovável contradição, expressando um recrudescente grau de insensibilidade ético-política diante de um cenário de injustiças? Por outro lado, as classes sociais poderiam ser solidárias e confiar umas nas outras em um contexto de desigualdade? Não seria desejável que fossem criadas associações civis para desestabilizar a ordem social desigual, dando origem a outro tipo de CS, por assim dizer, revolucionário? Para nós, além de empiricamente improvável, a vigência daqueles valores em meio a uma sociedade desigual e injusta seria normativamente indesejada.

Aduzindo à discussão da população jovem e marginalizada, os efeitos de um contexto de desigualdade a atingem diretamente. Vários artigos vêm discutindo a relação entre CS e juventude, focalizando o processo de socialização política da juventude no interior de sociedades democráticas em crise. A questão enfrentada é como mobilizar a juventude, engajando-a em práticas políticas associativas fundamentais à cultura cívica. O que Nazzari (2006) chama de agências de socialização política têm diversificado suas estratégias sobre a juventude empobrecida. Como já vimos, a ideia é que os concidadãos colaborem para incrementar a comunidade cívica, pois ela é condição de possibilidade para um "bom desenvolvimento". A confiança, ligada à previsibilidade das relações sociais, depende da cooperação entre as pessoas. A cooperação, por seu turno, depende da reciprocidade entre os membros e promove a participação em associações voluntárias.

É acerca deste conjunto de valores que a UNESCO tem fomentado a intervenção sobre a juventude, particularmente aquela mais expropriada de direitos sociais e classificada como em estado de vulnerabilidade social. A construção dos programas se baseia na cidadania, participação social e educação como fatores de coesão e protagonismo juvenil (NOLETO, 2001). A contestação da ordem - mesmo que injusta - está fora de escopo. Na medida em que não focalizam a reflexão crítica sobre a ordem, as chamadas pedagogias do corpo, destacando o esporte, são importantes estratégias de subjetivação contemporânea e de controle social, atuando em termos de domesticação e docilização de indivíduos (SOARES, 2006).

Nas políticas públicas voltadas para a juventude em situação de vulnerabilidade social no Brasil, advoga-se que uma condição para superação deste estado passaria pelo fortalecimento do CS, ampliando as formas de 
participação e protagonismo do jovem, para que ele se sinta capaz de lidar com o ambiente de incerteza e insegurança. Segundo Abramovay et al. (2002, p. 56), o acesso negado aos jovens latino-americanos a determinados bens como educação, saúde, trabalho, cultura e lazer estaria contribuindo para o fomento da violência juvenil como "uma forma de os jovens quebrarem com sua invisibilidade e mostrarem-se capazes de influir nos processos sociais e políticos da América Latina", entendimento que deveria, para nós, levar à conclusão de que atos tidos como violentos não são um problema em si a ser resolvido, mas sim um modo de denunciar e lutar contra um ordenamento social injusto, portanto, ações eminentemente políticas. Entretanto, não é isso que se vê, costumeiramente, nos discursos correntes.

Visando cumprir um papel protagonista como agente de socialização política, a UNESCO, por exemplo, tem como carro-chefe o programa Abrindo Espaços, que se destina a oferecer aos jovens e suas famílias atividades de cultura, esporte, arte, lazer e formação profissional nos fins de semana. A marca desta estratégia, que intenciona promover a diminuição dos índices de violência, é a sutileza e a dissimulação das estratégias utilizadas. Aliás, esta é uma marca da vertente pedagógica caracterizada como não formal, lúdica, não compulsória. Ao invés da experiência escolar (obrigatória), temos a livre e espontânea adesão dos indivíduos às práticas não obrigatórias, como a desportiva. A ideia é que o ensino das regras do jogo (do esporte e da sociedade) não sofre resistências, já que os indivíduos perceberiam tais práticas como lúdicas e espontâneas. Em outras palavras, eles aprendem a obedecer brincando do que mais gostam, o que é atestado pelo documento da organização: "com uma agenda 'aberta' de atividades e com significativo espaço para as iniciativas individuais, o programa lança as bases de uma nova visão a respeito de 'disciplina'. Suas regras são claras, mas tendem a ser combinadas com os participantes" (GOMES, 2008, p. 89).

Por outro lado, os projetos desportivos gozam de uma aprovação social que os legitima. Não se vê, via de regra, críticas à sua estrutura, ao salário e condições de trabalho dos profissionais envolvidos, tampouco ao cumprimento do que tais projetos prometem executar. Eles são apresentados como inquestionáveis formadores de cidadãos, como espaços de transformação que possibilitam a ascensão social. Cabe registrar que, 
ainda que o programa da UNESCO indique as escolas como principal locus para as atividades daquele programa, estas atividades são tidas como uma alternativa às práticas cotidianas de uma instituição (escolar) que não daria impulso às potencialidades dos jovens, pois são identificadas com tarefas, obrigações, coisas chatas e desinteressantes (NOLETO, 2001; GOMES, 2008). Além disso, como já dissemos, esses projetos desportivos reafirmam desejos e expectativas de mudança de vida veiculados midiaticamente, ainda que eles sejam sistematicamente frustrados (PIMENTA, 2008; SOUZA et al., 2008).

A relação entre $\mathrm{CS}$, educação e esporte para a prevenção da violência pode ser interpretada como parte de um conjunto de ações que visa promover a educação política da juventude, forjando uma noção de cidadania específica, ou ainda, uma cidadania cordata, para a qual o sumo bem são a paz e a ordem sociais (VILAÇA, 2010). Segundo Rodrigues (2006, p. 421), "o que se entende hoje por cidadania formal é precisamente a pertença individual (e, de certa forma, também coletiva) às regras do jogo". Keil (2004) afirma que o exercício da cidadania, no Brasil, nunca foi pleno. Atualmente, para a autora, a minguada cidadania brasileira é ainda mais mitigada, pois direitos têm se tornado bens de consumo, podendo, com isso, ser intercambiáveis, e deveres são vistos como obrigação, o que enfraquece seu caráter político. A juventude é estimulada a adotar certo modo de vida que lhe permita consumir, incluindo certos direitos. Em meio a isto, segundo Baquero e Hammes (2006), a UNESCO defende a necessidade e importância da participação cidadã da juventude.

A questão que logo se coloca é qual ação cidadã se espera que a juventude exerça. Os empreendimentos políticos apontam, sobretudo, para a ideia de formação política de jovens com vistas à postura associativa em prol da defesa de uma indistinta noção de bem comum. Os jovens devem reconhecer o valor do voluntariado e da coletividade, respeitar o próximo, as regras sociais vigentes, a lei, a diversidade, cultivando valores como confiança, civismo, empreendedorismo, entre outros (BAQUERO; HAMMES, 2006; KEIL, 2004). Com isso, a participação política que tem sido requerida dos jovens é de uma cidadania marcadamente conservadora da ordem vigente, embora esta seja produtora de desigualdades. Por conseguinte, ações políticas que a contestem, especialmente fora dos 
limites previstos em lei, não seriam legítimas. A cidadania é, então, colonizada pela paz e pela ordem, e variadas ações possíveis são proibidas sob a negativa insígnia da violência.

\section{Sobre violência e política}

No âmbito político, ações contra dada ordem estabelecida são sempre possíveis. Todavia, uma grande corrente, que congrega autores de diversas posturas intelectuais e ideológicas, parece concordar que há certos limites entre o que deve ser permitido e proibido. Dentre eles, destacase a violência. A violência e política constituem, para alguns, um par de oposição binária. Ou seja, quando e onde uma se institui e desenvolve, a outra padece. De saída, esta lógica precisa ser analisada, vez que poderia ser entendida como um falácia. Afinal, lembramos que a formação dos Estados tidos como modelos de regimes políticos democráticos se deu por meio da associação da acumulação de capital e do uso de meios violentos para dominar territórios e populações. Ademais, a ideia de monopólio estatal da violência, típica dos modelos liberais de governo, serve como mantenedora de tais regimes. Ou seja, violência e política estão mais intimamente ligadas do que se deseja admitir.

De acordo com Bobbio (2003), na história da filosofia política, todo problema pode ser visto pelo menos a partir de duas perspectivas: da parte do príncipe (ex parte principis) e da parte do povo (ex parte populi). A questão da violência está inserida nisto, pois "ex parte principis a violência justificada é aquela que serve à conservação do poder. Ex parte populi, porém, é geralmente justificada a violência oposta, aquela que tende não a conservar o poder tal qual ele é, mas a destruí-lo para substituí-lo por outro" (BOBBIO, 2003, p. 170).

O filósofo italiano denomina essa controvérsia como duas éticas da violência. Elas são diametralmente opostas e incompatíveis. Entre uma ação conservadora e uma revolucionária, estamos claramente diante da complexa questão da justificação da violência, o que se dá no campo tenso da política. Noutros termos, o que parece estar em choque são a violência institucionalizada ou estatal e a violência revolucionária, haja vista ambas requisitarem justificação precisamente tomando a outra como um problema 
(negativo), ao qual só se pode dar uma resposta através de uma violência (positiva).

Inobstante a ambiguidade citada, que nos parece digna de consideração, há aqueles que rejeitam qualquer possibilidade de avaliação positiva da violência. $\mathrm{Na}$ esteira de uma tradição extremamente diversificada, a violência foi paulatinamente perdendo espaço. Alguns dos filósofos políticos modernos mais conhecidos tematizaram, cada um à sua maneira, os limites da violência no âmbito do Estado. Entre os mais importantes filósofos políticos da modernidade, a violência era tema obrigatório, o que denota a sua importância. É conhecido o debate capitaneado por Locke, Rousseau e Hobbes acerca da necessidade da contenção, por parte do Estado, da violência. A guerra de todos contra todos, tão temida e combatida por Hobbes é um índice dessa preocupação que predominou no pensamento político doravante.

Kant também foi um apologeta da não violência. Posicionando-se inclusive contra a teoria da guerra justa, que levava em conta exclusivamente a guerra entre Estados, Kant (1995) rejeitou, na sua concepção de Estado, a preparação permanente para a guerra. Para ele, a paz perpétua assumiria um papel de ideal que deve regular as ações estatais. No terceiro artigo preliminar $^{4}$ de A paz perpétua [1795], Kant defendeu que os Estados não deveriam investir na preparação para a guerra, rejeitando a tese de que isso representaria uma forma indireta de se conquistar a paz. Para ele, a mobilização de indivíduos para matar ou morrer implicaria um uso dos homens como simples máquinas e instrumentos na mão de outrem, o Estado, contrariando uma das suas teses morais fundamentais: o homem não deve ser tratado exclusivamente como meio, mas sempre e ao mesmo tempo como fim em si mesmo (segunda formulação do imperativo categórico).

A perspectiva kantiana reverbera em alguns importantes pensadores contemporâneos do campo da filosofia política, tais como John Rawls e Jürgen Habermas. Um dos pontos fundamentais compartilhados é que há desacordos razoáveis típicos de sociedades liberais pluralistas, os quais são alvo de debate no terreno do espaço público sob condições políticas e

4 Intitulado Os exércitos permanentes (miles perpetuus) devem, com o tempo, desaparecer totalmente. 
morais que permitam que todas as perspectivas sejam defendidas. Nos casos em que as diferenças sejam inconciliáveis pelo debate, aposta-se no poder normativo do direito para a solução de conflitos. A violência, portanto, não é legal, nem legítima quando exercida por um indivíduo. Porém, exercida sob a égide legal, ou seja, pelo Estado, a violência é permitida, pois, supostamente, evitaria males maiores. Quer dizer, como um "mal que vem para bem", a violência não está fora do campo da política. Aliás, o Estado e a lei são frutos da violência e nela se esmeram (AMES, 2011). Em nome da "liberdade", violentou-se sobremaneira.

A socióloga Maria do Valle, a partir de uma postura críticomarxista, aponta como as revoluções burguesas, fundamentadas em parte no pensamento daqueles filósofos, trataram de retirar justamente o papel da revolução do cenário político. Isto, aparentemente contraditório - já que elas foram levadas a termo por meio da violência, incluindo assassinatos em massa, prisões arbitrárias, etc., a fim de eliminar o inimigo interno -, é um ponto-chave da estratégia liberal de conservação do seu sistema político. Segundo ela, "para a tradição liberal-conservadora, a questão social, a luta das classes trabalhadoras pela melhoria das suas condições de existência, é uma ameaça à ordem política voltada para a garantia das liberdades individuais" (VALLE, 2005, p. 13). Pelas liberdades individuais, ações coletivas de luta que contestem a ordem e a lei devem ser combatidas pelo aparato policial estatal. É evidente que isso expressa uma concepção política específica, e não uma verdade absoluta e inconteste.

Conquanto tal entendimento negativo constitua mais ou menos uma tradição de pensamento político com variados representantes, parece-nos que a complexa relação entre violência e política precisa ser (re)pensada. Entre outras coisas, as questões de quem pode exercê-la legitimamente, em quais situações, sob quais limites e contra quem permanecem atuais. Não pretendemos respondê-las, em absoluto, mas apenas indicar que a violência pode ser, ao contrário do que se pensa, um dos instrumentos tipicamente políticos. Entretanto, problematizando uma monovalência autojustificada da violência como algo negativo, cabe definir o que pode ser entendido como violência, ou violências, no plural.

Recorrendo à análise etimológica, o termo violência é uma derivação da palavra latina violentia, que significa a força que se usa contra o direito 
ou a lei (MISSE, 2006). Em alemão, uma mesma palavra (Gewalt) pode significar violência como força imposta e como poder no sentido da origem do direito (AGAMBEN, 2003). Para Bobbio (2003, p. 143), por violência, entendem-se três coisas fundamentais e inter-relacionadas: "(a) o uso da força física, (b) intencionalmente dirigida para o efeito desejado por parte do sujeito ativo, e (c) não consentida por parte do sujeito passivo".

De modo geral, segundo Misse (2006), o termo violência passou a ter dois sentidos predominantes, a saber, como qualquer coisa que rompa uma ordem ou o emprego de meios para impor uma ordem, corroborando aquela definição de Bobbio. A violência também está ligada a uma representação de intervenção física contundente sobre outrem (MISSE, 2006). No campo do agente, chama-se de violento (violentus) aquele que age com força excessiva, exagerada (MISSE, 2006). Embora seja ressaltado que deve-se falar em violências, no plural, um sentido negativo de violência parece preservado, isto é, algo fundamentalmente contra e excessivo. Ademais, não é contra qualquer coisa, mas geralmente contra as que são tidas como boas, positivas, desejáveis. Assim, se tudo que é violento põe em risco algumas das coisas que mais se reputa, presume-se que o que identificamos com a violência seja tido como negativo.

A visão negativa dos modernos é encontrada também em pensadores contemporâneos, mesmo naqueles que não defendem a democracia e um primado do direito. Michel Foucault é um exemplo. Para ele, violência pode ser entendida como a ação que suprime as relações de poder. Ou seja, um ato violento ocorre quando o sujeito das ações sobre as quais se quer exercer o poder não é mais reconhecido como sujeito, virando um objeto, para o qual estão extintas as possibilidades de resistência (FOUCAULT, 2001). Além disso, ele define, "uma relação de violência atua sobre o corpo ou sobre as coisas" - diferentemente das relações de poder, que são ações atuando sobre ações - "forçando-os, abatendo-os, quebrando-os, destruindo-os, fechando-os a porta de toda possibilidade" (FOUCAULT, 2001, p. 253). Segundo Foucault, violentas seriam as ações que aspiram à dominação absoluta, inconteste e irreversível, que solapa a possibilidade da liberdade de resistência.

Outro importante exemplo é a pensadora alemã Hannah Arendt. Ela dedicou-se a defender a separação entre política e violência (TORRES, 
2007), posicionado-se flagrantemente contra o uso desta para fins políticos. Para ela, violência e política-poder têm substâncias diferentes (ARENDT, 2009). O poder é afeito à dimensão da legitimidade, da autoridade, da potência e constituição política (AGUIAR, 2011). A violência é o mal predileto dos regimes totalitários. Aguiar (2011) afirma que eles associam ao mal radical toda a violência extremada e sistemática. Por exemplo, Arendt identificava nas novas formas de controle e dominação dos humanos analisadas no Origens do totalirismo [1951] vias de implementação da lógica da violência, da guerra e da morte (AGUIAR, 2011).

A noção de questão social em Arendt é fundamental para entender a sua postura em relação à violência, especificamente aquela que se (auto) denomina de revolucionária. De acordo com Aguiar (2004), Arendt, contra a sacralização que prevalece entre os que ontologizam o social, uma crítica clara ao marxismo, aposta na contraposição entre a quaestio facti e a quaestio juris. Arendt se posicionava ao lado daqueles que apostam nas vias institucionais, e apenas nelas, para a solução de questões sociais lato sensu. Se a questão social importa, há algo que deve transcendê-la, a saber, a questão de direito ou de validade, que, com sua potência normativa, deve regular aquela.

A questão social para Arendt, conforme Aguiar (2004), ganha um sentido próprio na Revolução Francesa. Em função da iniciativa que esta teve de formular uma nova ordem política, novas demandas surgiram, notadamente, as lutas por liberdade. Entretanto, segundo Arendt (1990), a liberação vilipendiou a liberdade, à medida que a necessidade sobrepôsse à liberdade enquanto justificação da revolução. A urgência da questão social, leia-se a solução da pobreza e da fome, tornou a fundamental luta pela liberdade algo secundário. Segundo Aguiar (2004, p. 15), “o contato com a questão social fez com que a revolução absolutizasse a liberação, a superação da penúria e da miséria como finalidade revolucionária".

Como, para Arendt, toda iniciativa de investimento na resolução de problemas atinentes à liberação relativiza o aspecto normativo da liberdade, há um risco, pois "a questão social como saída revolucionária única aponta para a solução revolucionária totalizante" (AGUIAR, 2004, p. 15). Diante da "ditadura da natureza", no sentido arendtiano de necessidades, qualquer instituição ou alto valor sociopolítico se torna uma espécie de luxo. 
Logo, ocorreria uma espécie de colonização da liberdade pela liberação, submetendo um valor normativo à urgência da satisfação das necessidades imediatas. Conforme Aguiar (2004, p. 15), "a liberação da necessidade passou a ter prioridade sobre a edificação da liberdade e o resultado foi a instituição da revolução permanente, da violência ilimitada, o terror, e não a fundação de uma nova constitutio libertatis, um corpo de iguais".

Um ponto controverso é como pode haver um corpo de iguais sem solucionar questões sociais. Arendt tem razão ao supor que medidas e regimes autoritários possam ser gerados sob a alegação de estarem lutando por uma questão social. Entretanto, para nós, além de uma coisa não derivar necessariamente da outra, não está claro que necessidades vitais sejam concorrentes da liberdade. Aliás, a sua satisfação é uma das condições de possibilidade de sermos livres e iguais. Ou seja, a questão social é eminentemente uma questão política, devendo ser considerada de modo complexo. Ao passo que não se garante liberdades exclusivamente com distribuição igualitária de recursos que propiciem a satisfação de necessidades naturais, não há liberdade e igualdade sem ela.

Outro ponto que nos parece problemático diz respeito a certo idealismo político de cunho aristotélico. Explicamos: sua crítica às modalidades de governo (controle e domínio) é parcial, pois volta-se para determinados regimes tidos como totalitários. Cumpre questionar, porém, que regime político não tem traços totalitários, quer dizer, não desenvolve práticas violentas extremadas e sistemáticas pelo menos contra dada parcela da população. A política, como um conjunto de ações e não um ideal, não seria um campo, por assim dizer, ontologicamente de violências, ainda que em graus diversos e sobre certos indivíduos? Feliz ou infelizmente, na política, como destaca Foucault (1995), convergem vida e morte. Além disso, no espírito maquiavélico, a lei, que deveria mediar desacordos e conflitos, coibindo a violência, é um produto da violência. "A violência que funda o Estado é a mesma a qual constitui a lei, pois tanto o Estado quanto a lei visam a abolir a violência originária existente "antes" ou "à margem" de todo ordenamento estatal e legal" (AMES, 2011, p. 22).

Diverso de uma tradição hegeliano-marxista, que afirma que a questão social é a principal questão política, dando lugar legítimo e, circunstancialmente, necessário à violência com vistas à revolução 
(VALLE, 2005), esse posicionamento arendtiano é um exemplar da clássica posição liberal acerca da negatividade da violência. Em suma, enquanto uma tradição hegeliano-marxista toma a violência como um instrumento para solucionar a questão social, (MORFINO, 2007), legitimando-a; uma tradição liberal, da qual Arendt é partícipe, toma a violência como fruto do deletério império da questão social sobre a liberdade individual.

Os pensadores citados, por motivações teóricas diferentes, com propostas políticas por vezes incompatíveis, concordam que a violência é um problema. Compreendida negativamente, ela está constantemente relacionada ao comprometimento da coesão e cooperação sociais, alguns dos elementos fundamentais do CS. Como problema, a violência deveria ser combatida. Todavia, compreendida desse modo restrito, há pelo menos duas consequências que nos parecem problemáticas: (1) a violência perde o seu valor de fenômeno social a ser estudado, virando apenas um problema social a ser solucionado; (2) ações de resistência ou contestação da ordem (injusta e desigual) para além dos limites da lei, pois esta tende a conservála, são estrategicamente rotuladas como violentas, o que as deslegitimaria.

Esta perspectiva reducionista de violência merece ser retorquida, à medida que a lógica que representa não oferece saída possível a um ordenamento jurídico que seja injusto e desigual, a não ser por meio dele mesmo, o que, diga-se de passagem, é uma brilhante estratégia de conservação da ordem. Essa perspicaz estratégia de dominação encontra um álibi no discurso de que cabe aos sujeitos-cidadãos endossar o sonho democrático. O cidadão é conclamado a cooperar com o Estado para que esse se torne plenamente democrático. Contudo, observa-se que os meios de cooperação aos quais os sujeitos têm acesso estão todos ou bem nas mãos do Estado, ou bem sob sua tutela vigilante. Com isso, não é qualquer ação ou comportamento que será permitido para que se catalise o processo de democratização.

Violência não é apenas um conceito, mas um ato sobre e contra alguém (MISSE, 2006; 2008). Essa atividade é prenhe de intencionalidades, pois, ao definir alguém ou alguma coisa como violento(a), tomase obrigatoria e imediatamente partido numa situação. Assim sendo, denominar um sujeito, uma prática ou um campo de ação inteiro de violento é assumir uma posição contrária a eles. Assume-se um juízo de 
valor acerca da própria ação e daquilo sobre o que ela age, negativando a primeira e positivando esse. Há, portanto, uma clara investida na solução pacífica, enquanto a via política por excelência.

Do ponto de vista do liberalismo político clássico, quando alguém age em desacordo com as leis, ele "rasga" o contrato, compromete sua manutenção, tornando-se uma ameaça à ordem social. Em termos antigos, torna-se um estrangeiro em seu próprio país, o que permite que certos direitos lhe sejam tirados. Pode ser o direito à liberdade, ao voto ou, no limite, à vida. De cidadão, passa a delinquente. Todo indivíduo tachado como violento é um delinquente. Destarte, a violência seria “[...] o emprego da força ou da dominação sem qualquer legitimidade" e, por conseguinte, "é violento aquele de quem se diz que não pode usar da força e a usa, ou aquele de quem se diz que abusa do poder que lhe foi conferido [...]" (MISSE, 2006, p. X). Forja-se o homo criminalis, uma subjetividade criminosa objetivada, uma "espécie perigosa" que é alvo de um campo de conhecimento, uma criminologia.

Todavia, contra a negativização da violência e a separação radical entre ela e a política, podemos, com Adolfo Sánchez Vasquez, considerar a violência como parte da práxis humana. De acordo com Vasquez (2011), uma ação violenta representa uma alteração ou destruição sobre um objeto real, físico, visando a destruir a sua resistência física. Ademais, por violência, o autor entende uma atividade humana que detém, desvia e, finalmente, altera uma legalidade natural ou social. A violência seria manifestada num ato de contrarresistência do humano a algo que, natural ou social, resistelhe. Para ele, a violência é um tipo de atividade exclusivamente do Homem, "na medida em que ele é o único ser que para manter-se em sua legalidade propriamente humana necessita violar ou violentar constantemente uma legalidade exterior (a da natureza)" (VASQUEZ, 2011, p. 374). Como vimos, a violência tem o poder de instituir ou destituir ordens. "Na sociedade dividida em classes antagônicas, a violência é a razão última do Estado", assevera Vasquez (2011, p. 379).

É indiscutível o papel central da violência na instituição do Estado moderno, das democracias. Pela violência, institui-se o regime de governo tido como ideal e é através dela que ele segue sendo instituído e mantido ao redor do mundo. Contudo, o discurso democrático não convive bem 
com a violência. Segundo Vasquez (2011), a democracia a trata como algo externo, como um mal necessário, encobrindo a relação íntima entre ambas. $\mathrm{O}$ apelo à força não violenta da lei, o elogio à ordem e à paz é um modo perspicaz de tentar convencer as pessoas de que elas não podem "fazer justiça com as próprias mãos" ou algo semelhante.

Assim, parece-nos fundamental resgatar a função eminentemente política da ação violenta, problematizando a acepção restrita e contraditória que o liberalismo político impingiu a ela, já que muitos dos seus valores mais caros, tais como Direitos Humanos, liberdade e democracia, foram "conquistados", disseminados e mantidos justamente pela violência. Além disso, à semelhança de Vasquez, a retomada da violência como uma dimensão incontornável da práxis humana, da política, ao contrário do que alguns críticos sugerem, não a naturaliza em todas as suas formas. Como coisa política, deve ser questionada e criticada quanto ao que pretende destituir e instituir, sem, contudo, ser absolutamente abominada em nome de uma "santa paz" prenhe de injustiças violentas.

\section{Críticas finais}

Muitas são as estratégias utilizadas para alcançar o quadro ideal de uma comunidade cívica fundada na cooperação e confiança, pautada pela paz e contra a violência, promovendo uma democracia. Os discursos sobre o papel socioeducativo do esporte constituem uma rede argumentativa com pretensões normativas. Isto é feito por meio de uma retórica de apologia de valores que estariam na interface esporte/sociedade: igualdade de condições, inclusão, superação de limites, disciplina, solidariedade, cooperação, o espírito de luta e de equipe. E o esporte os ensinaria, formando um "bom cidadão".

"O esporte educa, inclui, transforma", ouve-se insistentemente dizer. Supondo que sim, como defendem Azevedo e Gomes Filho (2011), cumpre-se questionar: como, em que sentido e cumprindo quais interesses? Será que o tipo de inclusão realizado é satisfatório? A transformação é suficiente para mudar a condição de vida da população? Quem se beneficiaria com o "êxito" da prática pedagógico-desportiva? 
Há uma argumentação insidiosa em torno da apologia do papel educativo dos esportes. Como exemplo, o recente artigo de Azevedo e Gomes Filho (2011) faz uma verdadeira ode à múltipla dimensionalidade benfazeja do esporte. Defende-se que ele é um direito e tem valor ético, proporcionando benefícios relativos ao lazer, à diversão, educação, participação, sociabilização, descoberta de novos talentos, competição e inclusão. Conforme já anunciamos, nosso ponto não é desvalorizar a prática desportiva. Ao invés, nossa tese é a de que é necessário precisar e contextualizar o seu valor. Falta nitidez do que é defendido. Por exemplo, não há apenas uma forma de socializar. Afinal, tal ato pressupõe uma concepção de sociedade real ou ideal. $\mathrm{O}$ ato da inclusão não é bom em si. Aliás, os pobres não estão completamente excluídos, embora isto não atenue os problemas decorrentes das desigualdades. Há uma dinâmica complexa e perversa que envolve exclusões e inclusões, já que a pobreza que exclui é condição de possibilidade da inclusão dos indivíduos em certas funções sociais e profissionais. Assim, é fundamental definir de que tipo e nível de inclusão se está falando, além de problematizar os seus efeitos sobre dada ordem vigente, reflexão rara entre os apologetas da prática pedagógico-desportiva.

Se o artigo supracitado exemplifica a tese de que há imprecisão na literatura científica, o estudo desenvolvido por Vilaça (2009) mostra como o mesmo ocorre no caso dos discursos midiáticos. Segundo ele, não é possível identificar o que a mídia defende, a não ser de modo interpretativo. Ou seja, cabe aos receptores dos discursos penetrar a tacitidade do que é dito, a fim de encontrar os seus significados. Isso seria possível, por exemplo, por meio de uma análise comparativa de pontos do discurso, o que permitiria inferir algumas relações. Contudo, a propaganda a favor do esporte também é marcada pela imprecisão.

Em meio à imprecisão que caracteriza os argumentos em prol da panaceia desportiva, alguns pontos são identificáveis. Uma das coisas que está em jogo é a ordem social. A tese é a de que como o esporte, enquanto algo institucionalizado, tem regras estabelecidas oficialmente a serem seguidas, punições previstas para quem as descumprirem, recompensas determinadas, árbitro, etc., ele é um análogo ao contexto sociopolíticodemocrático. Assim, quem aprende a respeitar o ordenamento desportivo, 
está preparado para aceitar o social. Toda ordem social tem suas regras. Todo esporte tem regras. A analogia é quase imediata. Elias e Dunning (1992) são pioneiros na análise sociológica do esporte como um meio de compreender a sociedade moderna, diferenciando-a das sociedades antigas e medievais. Segundo eles,

vários tipos de desportos integram um elemento de competição. São confrontos que envolvem força física ou proezas de tipo não militar. Para reduzir os danos físicos ao máximo, existem regras que obrigam os adversários a adotar um determinado tipo de comportamento. Desse modo, por trás destes estudos do desporto, existe sempre a pergunta: que espécie de sociedade é esta onde cada vez mais pessoas utilizam do seu tempo de lazer na participação ou na assistência a estes confrontos não violentos de habilidades corporais a que chamamos de "desporto"? (ELIAS; DUNNING, 1992, p. 40, grifo do original).

Como uma prática corporal que possui elementos que auxiliam a compreender a formação da sociedade, o seu processo civilizatório, o esporte moderno aparece na citação, dentre outras coisas, na forma de uma disputa não violenta. Como mostramos, a violência (não praticada pelo Estado) é tida como um mal e a paz como um bem. Se o esporte tem essa característica de regular as disputas, a fim de coibir a violência, parece sugestiva a relação entre a prática pedagógico-desportiva e uma cultura de paz. Associados àqueles valores supracitados, o respeito à lei e à autoridade formam uma rede normativa que visa a constranger, a normalizar condutas, a fim de que dada ordem não seja radicalmente posta em xeque. A ordem depende da paz, e esta depende de um investimento sobre a modalização do comportamento humano. E, aparentemente, o esporte contribuiria para isso.

Elias foi um estudioso do controle das pulsões e dos comportamentos. No caso da obra que destacamos, as pulsões e comportamentos violentos são o foco. A partir do conceito de ciclo de violência, eles analisam os investimentos na sua atenuação:

O reconhecimento do facto de os divertimentos com as características de desportos terem tornado forma definida em Inglaterra, em ligação com o apaziguamento de um ciclo de violência e a sua resolução num 
confronto politico não violento, de acordo com regras, torna mais fácil a compreensão de que o desporto altera a sua função e o seu carácter se, uma vez mais, a mare das tensões e da violência dentro ou entre Estados se elevar. Caso isso aconteça, as tensões miméticas e a excitação controlada que com elas se relaciona podem perder as suas características especificas, bem como a oportunidade de uma resolução agradável das tensões, as quais estão no fulcro do desporto de lazer e de muitas outras atividades deste tipo (ELIAS; DUNNING, 1992, p. 72).

Tais passagens nos permitem inferir que o esporte, com sua lógica controlada e regrada, teria o poder de fazer com que as pulsões sejam liberadas de determinado modo. Ou seja, se antes elas eram liberadas em atividades "livres", desregradas e sem mediações preestabelecidas, por vezes dando origem a ações violentas, na prática desportiva, elas passam a ser experimentadas em um ambiente regulado. Isso poderia ultrapassar o contexto desportivo, extravasando pedagogicamente para o social, ensinando os indivíduos a como viver em sociedade por meio da prática desportiva.

Para nós, estamos diante de políticas públicas que são, concomitantemente, de esporte, lazer e segurança pública. Há pelos menos dois sentidos, que são traduzidos em dois focos: o sentido da prevenção, cujo foco está na tentativa de impedir que jovens pobres se tornem criminosos; e o sentido da proteção, haja vista os projetos sociais desportivos serem frequentemente percebidos como meios de evitar que os jovens tenham contato com os "perigos da rua", as "más influências" (VILAÇA, 2009; CASTRO; SOUSA, 2011).

Na medida em que um estado de violência ameaçaria a coesão em que se assenta a ordem social, as agências de socialização política, incluindo o Estado e as organizações internacionais, investem, sobretudo, em iniciativas que tenham o jovem como foco. Construir cidadãos (ordeiros) é a pedra de toque desses projetos em que os jovens são submetidos a um sistema disciplinar que viabiliza esse objetivo, o que dá corpo à discursividade que legitima esses projetos sociais como um ambiente de formação humana, tornando-os extremamente relevantes na contemporaneidade. Além disso, projetos como o Abrindo Espaços procuram legitimar-se perante as 
"ineficientes" escolas tradicionais, por meio de uma equivocada relação econômica de custo-benefício. Eles operam por meio de organizações na sociedade civil, através do financiamento de empresas privadas e fomento ao trabalho voluntário, o que resulta, segundo Rolim (2008), num custo equivalente a menos de $0,3 \%$ dos custos com os estudantes na rede pública de ensino. Através da lógica econômica neoliberal do "mais por menos", ou seja, supostamente obtém-se melhores resultados gastando-se menos. Assim, colocam no mesmo patamar uma rede de educação pública universal, que comporta uma gama de profissionais capacitados a intervir no processo educativo, e um projeto focal, operado em um número bastante inferior de escolas e com pessoal sem remuneração.

Consoante alguns estudos, tais investimentos são ineficientes e ineficazes (AREIAS; BORGES, 2011). Esta conclusão não é surpreendente, pois julgar que a prática desportiva seja suficiente para sanar problemas tão graves e complexos é, no mínimo, ingênuo. Isto não significa que ela não possa contribuir de algum modo para a formação de dada subjetividade política para dada concepção de sociedade, pelo contrário. No nosso entendimento, este é justamente um dos problemas. $\mathrm{O}$ esporte tem sido usado como forma de manter certa ordem social, embora adote uma retórica inversa, de transformação. Percebe-se, por exemplo, que o ponto fulcral da prática pedagógico-desportiva não são as razões ou causas das desigualdades, mas apenas seus efeitos. Resende e Andrade (2011) afirmam que a desigualdade de renda contribui para o aumento da criminalidade, sendo uma das suas causas básicas. Contudo, supondo que a manutenção das condições socioeconômicas, preservando a condição de marginalidade e pobreza dos jovens, fosse acompanhada de uma diminuição dos níveis de violência, os projetos sociais de cunho desportivo seriam, do seu ponto de vista, exitosos. Tal iniciativa estaria sendo capaz de forjar dada subjetividade, isto é, um conjunto de atitudes e valores, cujo papel é promover as bases de uma sociedade politica e economicamente desigual, tentando garantir a governabilidade. Destarte, a inclusão hipoteticamente realizada teria um valor sociopolítico que julgamos negativo, pois mantém uma ordem (desigual e injusta) por meio de uma espécie de acomodação pacífica dos indivíduos nela. Se a desigualdade não foi alterada e, apesar disso, os indivíduos se sentem incluídos, há um reforço do que deveria, do nosso ponto de vista, ser mudado. 
Supondo o condicionamento entre política e economia, o empobrecimento é um mal porque compromete certos bens fundamentais: direitos civis, sociais e políticos, tais como liberdades e igualdade de reconhecimento e acesso (por exemplo, à educação de qualidade, saúde, moradia, lazer, cultura, previdência, emprego, a cargos e funções públicos, etc.), os quais consubstanciam a cidadania e democracia (WOOD, 2006; RODRIGUES, 2006). Por só serem exercidas relativamente aos bens citados, as desigualdades devem ser combatidas por meio de iniciativas, estratégias, políticas e afins que sejam radicais. Nesse sentido, a postura que adotamos aqui, em conformidade com Wood (2006) e Frigotto (2004), é que não há como transformar jovens marginalizados em cidadãos sem garantir aqueles bens. Ou seja, a democratização de uma sociedade não é garantida simples e/ou necessariamente com obediências à ordem, lei e às autoridades, associadas à busca da paz. Por vezes, é imperioso o contrário. Considerando que uma organização política pode ser injusta e que a violência pode instituir ou destituir formas de poder (BOBBIO, 2003) como a história comprova, inclusive a da democracia liberal - a paz pode ser um tremendo aliado da manutenção de injustiças.

Entendemos que um processo pedagógico de inculcamento daqueles conceitos-valores sem uma reflexão sobre seus limites e suas consequências, por exemplo, para a conquista da cidadania acaba por simplificar os problemas sociais que se pretende resolver, ocultando determinantes socioeconômicos, bem como superestimando as soluções oferecidas.

Assim, por mais que haja a recorrente defesa da ideia da inclusão social, da cidadania, etc., se estas forem entendidas como um processo complexo e de longo prazo de igualização socioeconômica e política, nosso argumento é que, ao invés, estar-se-ia focalizando a pacificação social, a fim de contornar conflitos sociais decorrentes das desigualdades, sem superá-las. Em conformidade com aquilo que Foucault (2006b, p. 309) postula, a saber, que há tecnologias de governo utilizadas e desenvolvidas nos termos da razão de Estado, cuja finalidade é unicamente tornar o "indivíduo um elemento de peso para o Estado", algo útil e adequado para dada racionalidade política, parece-nos que a prática pedagógicodesportiva estaria, se muito, cumprindo esta estratégica função. 
Em face disso, concluímos que a prática pedagógico-desportiva é parte de um conjunto de investimentos na formação humana da juventude tida como em situação de risco social, a fim de que ela se ajuste a certo ordenamento e não que participe politicamente ao ponto de contestá-lo. Com isso, ela pode ser interpretada como uma estratégia social de conservação de uma ordem normativamente criticável. Ela visaria prioritariamente à propagação de alguns valores, que podem estar relacionados ao conceito de capital social, intentando construir e preservar uma ordem pacífica, sem, contudo, que isso implique uma alteração substantiva do contexto de flagrante desigualdade social, econômica e política que compromete a cidadania. A retórica panacéica da pedagogia desportiva possui generalizações e imprecisões, limites empíricos e normativos sérios, podendo falaciosamente dissimular interesses, investindo na formação de indivíduos para corroborar um modelo de sociedade sustentado por desigualdades e injustiças que merece ser repensado.

\section{Referências}

ABRAMOVAY, M. et al. Juventude, violência e vulnerabilidade social: desafios para as políticas públicas. Brasília: UNESCO/BID, 2002.

AGAMBEN, G. Estado de exceção. São Paulo: Boitempo, 2003.

AGUIAR, O. A. A questão social em Hannah Arendt. Trans/Form/Ação, v. 27, n. 2, p. 7-20, 2004.

. A dimensão constituinte do poder em Hannah Arendt. Trans/ Form/Ação, v. 34, n. 1, p. 115-130, 2011.

AMES, J. L. Lei e violência ou a legitimação política em Maquiavel. Trans/ Form/Ação, v. 34, n. 1, p. 21-42, 2011.

AREIAS, K. T. V.; BORGES, C. N. F. As políticas públicas de lazer na mediação entre estado e sociedade: possibilidades e limitações. Revista Brasileira de Ciências do Esporte, v. 33, n. 3, p. 573-588, 2011.

ARENDT, H. Da revolução. São Paulo: Ática/UNB, 1990. . Sobre violência. Rio de Janeiro: Civilização Brasileira, 2009. 
AZEVEDO, M. A. O.; GOMES FILHO, A. Competitividade e inclusão social por meio do esporte. Revista Brasileira de Ciências do Esporte, v. 33, n. 3, p. 589-603, 2011.

BAILEY, R. Evaluating the relationship between physical education, sport and social inclusion. Educational Review, v. 57, n. 1, p. 71-90, 2005.

BAQUERO, R.; HAMMES, L. J. Educação de jovens e construção de capital social: que saberes são necessários? In: BAQUERO, M.; CREMONESE, D. (Org.). Capital social: teoria e prática. Ijuí: Unijuí, 2006, p. 227-250.

BEUTLER, I. Sport serving development and peace: achieving the goals of the United Nations through sport. Sport in Society, v. 11, n. 4, p. 359-69, 2008.

BOBBIO, N. O problema da guerra e as vias da paz. São Paulo: Editora UNESP, 2003.

CASTRO, S. B. E.; SOUZA, D. L. Significados de um projeto social esportivo: um estudo a partir das perspectivas de profissionais, pais, crianças e adolescentes. Movimento (UFRGS), v. 17, n. 04, p. 145-163, 2011.

CORREIA, M. M. Projetos sociais em educação física, esporte e lazer: reflexões preliminares para uma gestão social. Revista Brasileira de Ciências do Esporte, v. 29, n. 3, p. 91-105, 2008.

D'ARAUJO, M. C. Capital social. Rio de Janeiro: Jorge Zahar Ed., 2003. DOMINGUES, E. P. et al. Quanto vale o show? Impactos econômicos dos investimentos da Copa do Mundo 2014 no Brasil. Estudos Econômicos, v. 41, n. 2, p. 409-439, 2011.

ELIAS, N.; DUNNING, E. A busca da excitação. Lisboa: DIFEL, 1992.

FOUCAULT, M. Post-scriptum. El sujeto y el poder. In. DREYFUS, H. L. e RABINOW, P. Michel Foucault: más allá del estructuralismo y la hermenéutica. Buenos Aires: Ediciones Nueva Visión, 2001. p. 241-259. . Em defesa da sociedade. São Paulo: Martins Fontes, 2005. . A hermenêutica do sujeito. 2. ed. São Paulo: Martins Fontes, $2006 a$. 
- A tecnologia política dos indivíduos. In: Ditos e Escritos $V$ : ética, sexualidade e política. 2. ed. Rio de Janeiro: Forense Universitária, 2006b. p. 301-318.

FRASER-THOMAS, J. L. et al. Youth sport programs: an avenue to foster positive youth development. Physical Education and Sport Pedagogy, v. 10, n. 1, p. 19-40, 2005.

FRIGOTTO, Gaudêncio. Juventude, trabalho e educação no Brasil: perplexidades, desafios e perspectivas. In: NOVAES, R.; VANNUCHI, P. (Org.). Juventude e sociedade: trabalho, educação, cultura e participação. São Paulo: Fundação Perseu Bramo, 2004. p. 180-216.

FUKUYAMA, F. Confiança: as virtudes sociais e a criação da prosperidade. Rio de Janeiro: Rocco, 1996.

FURLANETTO, E. L. Instituições e desenvolvimento econômico: a importância do capital social. Revista de Sociologia e Política, v. 16, suppl., p. 55-67, 2008.

GOMES, C. A. Abrindo espaços: múltiplos olhares. Brasília: UNESCO, 2008.

KANT, I. A paz perpétua e outros opúsculos. Lisboa: Edições 70, 1995.

KEIL, I. M. Dos jovens contestadores aos jovens de hoje. Uma nova forma de participação na polis? In: BAQUERO, Marcello (Org.). Democracia, juventude e capital social no Brasil. Porto Alegre: Editora da UFRGS, 2004, p. 17-48.

MELO, M. P. de. Lazer, esporte e cidadania: debatendo a nova moda do momento. Movimento, v. 10, n. 2, p. 105-122, 2004.

MISSE, M. Crime e violência no Brasil contemporâneo. Rio de Janeiro: Lumen Juris, 2006.

MORFINO, V. A sintaxe da violência entre Hegel e Marx. Trans/Form/ $A c ̧ \tilde{a} o$, v. 31, n. 2, p. 19-37, 2007.

NAZZARI, R. K. Capital social, cultural e socialização política: a juventude brasileira. In: BAQUERO, M.; CREMONESE, D. (Org.). Capital social: teoria e prática. Ijuí: Unijuí, 2006, p. 203-226. 
NOLETO, M. J. (Coord.). Abrindo espaços: educação e cultura para a paz. Brasília: UNESCO, 2001.

PIMENTA, C. A. M. O sonho na sociedade contemporânea: juventude e futebol. Ponto-e-vírgula, v. 3, p. 112-129, 2008.

PUTNAM, R. D. Comunidade e democracia: a experiência da Itália moderna. Rio de Janeiro: FGV, 2007.

RESENDE, J. P.; ANDRADE, M. V. Crime social, castigo social: desigualdade de renda e taxas de criminalidade nos grandes municípios brasileiros. Estudos Econômicos, v. 41, n. 1, p. 173-195, 2011.

RODRIGUES, J. Qual cidadania, qual democracia, qual educação? Trabalho, Educação e Saúde, v. 4, n. 2, p. 417-430, 2006.

ROLIM, M. Mais educação, menos violência: caminhos inovadores do programa de abertura das escolas no fim de semana. Brasília: UNESCO, Fundação Vale, 2008.

SANTOS, E.; BAQUERO, M. Democracia e capital social na América Latina: uma análise comparativa. Revista de Sociologia e Política, n. 28, p. 221-234, 2007.

SANTOS, M. L.; ROCHA, E. C. da. Capital social e democracia: a confiança realmente importa? Revista de Sociologia e Política, v. 19, n. 38, p. 43-64, 2011.

SOARES, C. L. Pedagogias do corpo: higiene, ginásticas, esporte. In: RAGO, M.; VEIGA-NETO, A. (Org.). Figuras de Foucault. Belo Horizonte: Autêntica, 2006. p. 75-86.

SOUZA, C. A. M. et al. Difícil reconversão: futebol, projeto e destino em meninos brasileiros. Horizontes Antropológicos, v. 14, n. 30, p. 85-111, 2008.

TORRES, A. P. R. O sentido da política em Hannah Arendt. Trans/Form/ Ação, v. 30, n. 2, p. 235-246, 2007.

VALLE, M. R. A violência revolucionária em Hannah Arendt e Herbert Marcuse: raízes e polarizações. São Paulo: Editora UNESP, 2005.

VASQUEZ, A. S. Práxis e violência. In: . Filosofia da práxis. 2. ed. São Paulo: Expressão Popular, 2011, p. 373-404. 
VIANNA, J. A.; LOVISOLO, H. R. Projetos de inclusão social através do esporte: notas sobre a avaliação. Movimento (UFRGS), v. 15, n. 03, p. 145-162, 2009.

- A inclusão social através do esporte: a percepção dos educadores. Revista Brasileira de Educação Física e Esporte, v. 25, n. 2, p. 285-296, 2011.

VILAÇA, M. M. Vida e violência em jogo: o esporte como prática pedagógica e exercício biopolítico. 2009. 216 p. Dissertação (Mestrado) - Faculdade de Educação, Universidade Federal do Rio de Janeiro, Rio de Janeiro, 2009.

- Capital social, esporte e juventude: notas sobre uma nova tecnologia social de pacificação. Educação On-Line (PUC-RJ), n. 7, p. 1-11, 2010.

WOOD, E. M. Democracia contra capitalismo. São Paulo: Boitempo, 2006.

Data de registro: $11 / 05 / 2012$

Data de aceite: 19/06/2013 